\title{
Kienbock's disease and juvenile idiopathic arthritis
}

Nicholas M. Desy*, Mitchell Bernstein, Edward J. Harvey, Elizabeth Hazel

ABSTRACT: Kienbock's disease or osteonecrosis of the lunate is an uncommon cause of wrist pain. . Though there have been several reports of cases in patients with various rheumatologic diseases, the precise etiology has currently not been established. We report a case of Kienbock's disease that occurred in a patient with juvenile idiopathic arthritis. To our knowledge, this is the first case report with an association between these two conditions.

Keywords: Kienbock's disease, osteonecrosis, juvenile idiopathic arthritis, lunatomalacia,

\section{INTRODUCTION}

The etiology of Kienbock's disease, also known as (osteonecrosis of the lunate, remains controversial. It commonly occurs in patients twenty to fourty years old and presents with pain and stiffness in the dorsomedial aspect of the wrist. Several risk factors have been established to help explain its etiology: acute or repetitive trauma, variation in blood supply to the lunate, differences in the anatomy and shape of the lunate bone, and venous congestion $(1,2)$. Abrormal biomechanics at the radiocarpal joint between the distal radius and ulna has also been implicated in Kienbock's disease $(3,4)$. Ulnar variance describes the length relationship between the articular surfaces of the radius and ulna at the radiocarpal joint. Positive ulnar variance indicates that the ulna is longer than the radius, while negative ulnar variance indicates that the ulna is shorter at the wrist joint. In neutral ulnar variance $80 \%$ of the axial load at the wrist is transmitted through the distal radius. As ulnar variance decreases to more negative values, the "To whom correspondence should be addressed:
Dr. Nicholas M. Desy load transmission across the distal radiocarpal joint increases, subsequently exposing the lunate to abnormally higher pressures and potentially increasing the risk of Kienbock's disease $(3,4)$. Kienbock's disease is also associated with systemic lupus erythematosus (SLE) (5-8), antiphospholipid antibody syndrome (9), sickle cell anemia (10), and Crohn's enteritis (11) Multiple hereditary osteochondromata (12), carpa coaltion $(13,14)$ and congenital shortening of the ulna in Langer-Giedion syndrome (15), are other anatomic abnormalities that have been reported with Kienbock's disease. Rheumatic diseases, including scleroderma (16-18), rheumatoid arthritis $(19)$, gout $(20,21)$ and dermatomyositis $(22)$ have been published in association with Kienbock's, but there have been no identifiable cases in patients with juvenile idiopathic arthritis (JIA). This report presents a case of osteonecrosis of the lunate in a patient with JIA and no prior history of trauma. Furthermore, a literature review is done to illustrate the proposed etiologies of Kienbock's disease and its association with other rheumatologic conditions.
CASE REPORT

A 20-year-old right-handed female with known rheumatoid factor negative polyarticular JIA presented to the clinic because of pain and limited range of motion in the left wrist. had collapse of the lunate with mixed signal Inar variance, sclerosis, and loss of lun negative (Fig 1). The imaging was compatible with Stagh (Fig. 1). The imaling was compallole with Stage osteonectis of the was compate (23). The patlent was managed non-operatively and at two-year follow-up was asymptomatic with no concomitant wor nine after a two month history of with recealionat actives Durng the cours of hy illness several outhes. Durng the course of her involved oun joints progressively became involved. During the first year of treatment, she was prescribed nonsteroidal anti-inflammatory medication and low-dose prednisolone. To help control her symptoms she required diseasemodifying antirheumatic drugs. Her medications included methotrexate $20 \mathrm{mg}$ weekly, folinic acid $2.5 \mathrm{mg}$ weekly, and etanercept $25 \mathrm{mg}$ twice a week. Three weeks prior to presentation, the patient experienced a severe flare of her arthritis due to non-compliance with her medication. This lead to persistent left wrist pain and limited rangeof-motion. On examination she demonstrated synovial thickening of her left wrist with no palpable effusion.

Magnetic resonance imaging of her left wrist showed mild synovial thickening and erosive arthropathy throughout the carpus, and erosive and carpomy is possible sclerosis and edema, since she

\section{DISCUSSION}

The etiology of Kienbock's disease remains unclear(Table 1). The current literature indicates that most cases of Kienbock's disease develop withou a history of trauma and posit that e extraosseous and intraosseous blood supply to the lunate have a role in the disease process. The extraosseous blood supply is formed by a series of dorsal and volar vascular arches $(1,24)$. The intraosseous blood supply is made up of braches entering the volar and dorsal poles however the composite of this vasculature is variable (1, 25-27); branches demonstrate different anastomosis patterns inside the lunate, or the lunate may be supplied by only one dorsal or volar branch or By both a dorsal and volar arterial supply the lunate without any anastomosis (26). When an anastomosis does exist, it can be characterized as a $Y X$, or I pattern, depending the amount of ves, $X$, or $l$ pattern, depending on Depending on the intraosseous vascular antomy

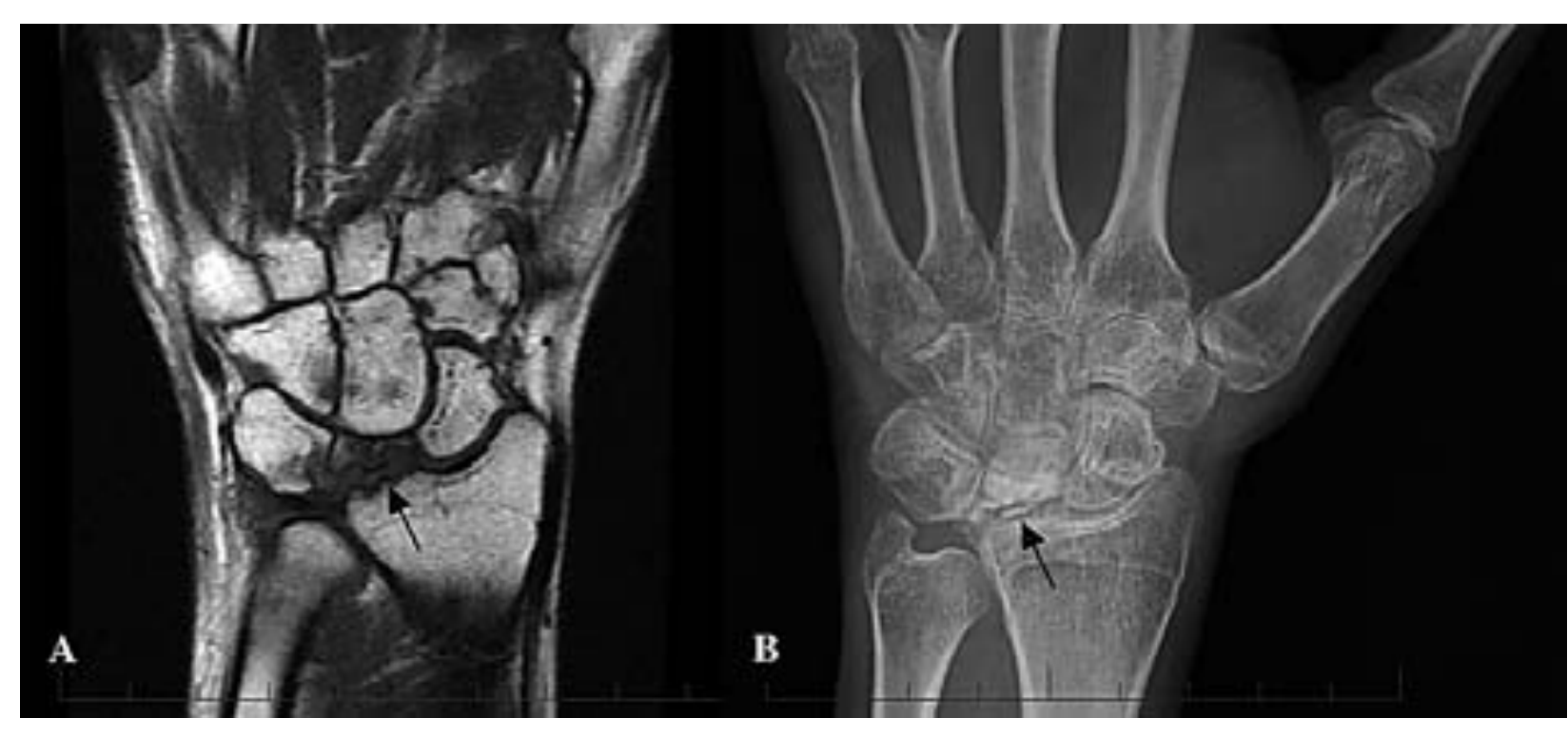
Figure 1: A. Coronal T1-weighted fast-spin-echo magnetic resonance image showing collapse of the lunate with mixed signal in-
tensity suggesting sclerosis and edema consistent with Kienbock's disease (arrow). Erosive arthropathy throughout the carpus and

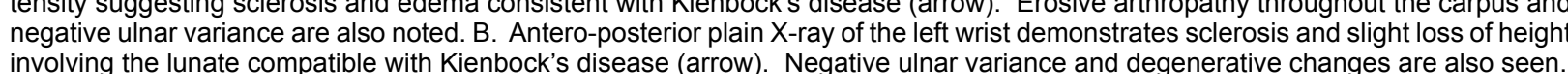


Current proposed mechanisms Aberrant blood supply to the lunate

Abnormal risk biomechanics

Endothelial cell dysfunction

Increased intraosseous pressure

Microvascular thrombophilia

Trauma-induced with disruption of the blood supply

\section{Venous congestion}

Table 1: Pathogenesis of osteonecrosis of the lunate

of the lunate, certain lunate bones are predisposed to Kienbock's disease. This concept was highlighted in a case report of Kienbock's disease associated with sickle cell anemia (10). The osteonecrosis was thought to have developed from an at-risk lunate single volar arterial supply - along with significant vascular sickling and stasis.

Venous congestion has also been attributed to the pathogenesis of Kienbock's disease (2). During surgery, Jensen measured increased pressure inside the lunate compared with the radial styloid and capitate. He concluded that the higher pressure was caused by venous congestion leading to osteonecrosis of the lunate.

Negative ulnar variance is also implicated in the pathogenesis of Kienbock's disease $(3,4$, 28). The altered relationship between the ulna and radius at the distal radioulnar joint modifies the biomechanics at the radiolunate joint and increases strains on the lunate. This postulation is still controversial because. This postulation including a meta-analysis, have shown that negative u mar varince is not a risk factor for cover developing Kienbock's disease, (29, 30). On the contrary, Ledoux et al. performed a finite-element analysis on cadcus peric that the progression of a fracture or the lunate was present with negative ulnar variance, a high lunate uncovering index, which is the amount of lunate outside the lunate fossa of the radius compared to the amount of lunate articulating with the lunate fossa, and angulated trabeculae (31). This suggests that given the circumstance, the lunate can be at risk for developing osteonecrosis due to abnormal stresses.

Further cases have also reportedpatients with conditions that may have caused altered stresses on the lunate. In particular, two cases have been reported involving carpal coalition $(13,14)$. It was postulated in these cases that carpal coalition caused a progressively increasing stress on the lunate, which in turn led to Kienbock's disease. Schuind et al. reported a case of Kienbock's disease associated with congenital shortening of the ulna as seen in Langer-Giedion syndrome (15). It was suggested that Kienbock's disease developed from microfractures sustained by an abnormal stress distribution (15). Multiple hereditary osteochondromata in the forearm was also found in association with Kienbock's disease and was attributed to an excess load on the lunate by negative ulnar variance, but with no carpal slip (12).

Systemic lupus erythematosus has been Sy 1977, Urman pros of patients of the carpal bones, ceport of a palient with SLE and Kienbock's disease (8). The patientalso had a history Raynaud's phenomenon and was taking highcorticots corticosteroids and who developed osteonecrosis, chere was one palient who developed Kienbock's disease (5). This patient was treated with large doses of corticosteroids compared to those who did not develop Kienbock's disease. Mok et al. reported a case of bilateral Kienbock's disease in a patien with SLE (6). The patient described in this case report was never treated with corticosteroids and the etiology of Kienbock's disease was thought to be due to a vasculopathy caused by either vasculitis or antiphospholipid antibodies, even though this patient tested negative for lupus anticoagulant and anticardiolipin antibodies. More recently, Taniguch et al. described two cases of Kienbock's disease in SLE after taking high doses of steroids (7) One of the cases was of a patient who developed bilateral osteonecrosis of the lunate. Both cases attributed corticosteroid use with the development of osteonecrosis. It is apparent that the cases of Kienbock's disease in patients with SLE were either attributed to high dose corticoste were or to the disease itself. Crohn's disease who itsel. More over, patients with control disease symptoms are known to develop control disease symptoms are known to develop Kip (11). The sease and osteonecrosis of the hip (11). The same scenario also occurred in a corticosteroids for sixteen months (22).
Scleroderma associated with Kienbock's disease was first reported by Agus et al. in a patient with bilateral osteonecrosis of the lunate (16). This patient had severe Raynaud's phenomenon and was never treated with corticosteroids. The contributing factors were hypothesized to be vasculopathy, Raynaud's phenomenon, and a lunate consisting of a single nutrient vessel. Ribbans also reported a case of Kienbock's disease in a patient with scleroderma and severe Raynaud's phenomenon (18). The vasculopathy, scleroderma, and repeated use of the patient's affected wrist predisposed this patient to Kienbock's disease. Matsumoto et al. reported three cases of Kienbock's disease in three patients with scleroderma, two without a history of steroid use and one who only used low dose steroids prior to the diagnosis of osteonecrosis (17). All three patients also had limited skin invols (17). but had pevere Raynaud's phenomenon. They but had sever repos was likely the cause of the circulatory impairment to osteonecrosis.

Mok et al. reported a patient with rheumatoid arthritis who was found to have osteonecrosis of the lunate. They believed that the Klenbocks disease occurred in this patent due to an increase in intra-articular pressure within the wrist compartment, causing return, vascular insufficiency to the lunate, and subsequent osteonecrosis (19).

In addition to the various risk factors mentioned above, Kienbock's disease $b$ is prevalent in specific patient populations. Rooker et al. found an increased prevalence of Kienbock's disease in a group of patients with cerebral palsy $(9.4 \%)(32)$. This was thought to be related to an abnormally flexed posture of a spastic wrist, which was present in all patients with Kienbock's disease in this study and could impede blood flow. Joji et al. also found an increased prevalence of Kienbock's disease in patients with cerebral palsy $(2.7 \%)(33)$. They believed that the high muscle tone across the wrist in an unar negative wristcaused an increased pressure on the lunte. This cause is consised pressue on the luster compromise and ulima

While the association between Kienbock's disease and several of the reported cases could be coincidental, having a meumatologic co- for Kienbock's disease, as seen in the presented case report. The wrist is the second most commo site of growth abnormality in patients with JIA (34). Several changes occur at the wrist, including narrowing of the intercarpal spaces, premature ossification of the carpal bones, and early fusion of the ulnar epiphysis leading to a shorter ulna (negative ulnar variance) (35). The wrist ultimately becomes displaced ulnarly and volarly leading to a dislocation of the wrist and bayonet deformity. Therefore, it is possible that the abnormalities in the wrist associated with JIA could lead to abnormal stresses and or pressures in the wrist that led to Kienbock's disease. Furthermore, the erosive changes in other carpal bones may lead to a change on the normal force patterns in the patient's carpus. Seven years prior to the inset of Kienbock's disease, our patient was also treated with low-d's disease, our palion was also treated 作 lisrupted circulation and led to the development of
lunate osteonecrosis. The precise etiology of Kienbock's disease remains elusive. Several theories attempt to explain its pathogenesis, which suggests that may be multifactorial. Many risk factors have also been identified, steroid treatment, a predisposing rheumatologic disease, a variation in lunate blood supply, and possibly negative ulnar variance. Ou case demonstrates the possible relation between Kienbock's disease and JIA. It also suggests that Kienbock's disease could be a possible cause of wrist pain and stiffness in patients with JIA.

Gelberman RH, Bauman TD, Menon J et al. The vascularity of the lunate bone
Am. 1980:5:272-278. Jensen $\mathrm{CH}$. Intrao

J Hand Surg Am. 1993;18:355-359.

Bonzar M, Firrell JC, Hainer M et al. Kienbock disease and negative ulnar variance. $J$ Bone Joint Surg Am. 1998;80:1154-1157

Chen WS. Kienbock disease and negative ulnar variance. $J$ Bone Joint Surg Am. 2000;82:143-144.

5. Griffiths ID, Maini RN, Scott JT. Clinical and radiological features of osteonecrosis in systemic lupus erythematosus. Ann Rheum Dis. 1979;38:413-422

6. Mok CC, Lau CS, Cheng PW et al. Bilateral Kienbock's disease in SLE. Scand J Rheumatol. 1997:26:485-487. 
7. Taniguchi Y, Tamaki T, Yoshida M. Kienbock's disease in systemic lupus erythematosus. Hand Surg. 2002:7:197200

8. Urman JD, Abeles M, Houghton AN et al. Aseptic necrosis presenting as wrist pain in SLE. Arthritis Rheum. 1977;20:825-828.

9. Alijotas J, Argemi M, Barquinero J. Kienbock's disease and antiphospholipid antibodies. Clin Exp Rheumato. 1990;8:297-298.

10. Lanzer W, Szabo R, Gelberman R. A vascular necrosis of the lunate and sickle cell anemia. A case report. Clin Orthop Relat Res. 1984:168-171.

11. Culp RW, Schaffer JL, Osterman AL et al. Kienbock's disease in a patient with Crohn's enteritis treated with corticosteroids. J Hand Surg Am. 1989;14:294-296.

12. de Gauzy JS, Kany J, Darodes P et al. Kienbock's disease Hand Surg Am. 1999;24:642-646.

13. Kaneko $\mathrm{K}$, Uta $S$, Mogami $A$ et al. Lunatomalacia in ascocition with congentat synostosis between

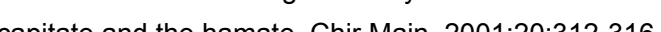

14. Macnicol MF. Kienbock's disease in association with carpa coalition. Hand. 1982;14:185-187.

15. Schuind FA, Schiedts D, Fumiere E et al. Lunatomalacia Schuind $F A$, Schiedts $D$, Fumiere $E$ et al. Lunatomalacia
associated with congenital shortening of the una in associated with congenital shortening of the ulna 1997;22:404-407.

16. Agus $B$. Bilateral aseptic necrosis of the lunate in systemic sclerosis. Clin Exp Rheumatol. 1987;5:155-157.

17. Matsumoto AK, Moore R, Alli $P$ et al. Three cases of osteonecrosis of the lunate bone of the wist in scleroderna. Clin Exp Rheumatol. 1999;17:730-732.

18. Ribbans WJ. Kienbock's disease: two unusual cases. J Hand Surg Br. 1988;13:463-465

19. Mok CC, Wong RW, Lau CS. Kienbock's disease rheumatoid arthritis. Br J Rheumatol. 1998;37:796-797.

20. Castagnoli M, Giacomello A, Argentina RS et al. Kienbock's disease in gout. Arthritis Rheum. 1981;24:974-975.

21. Shin AY, Weinstein LP, Bishop AT. Kienbock's disease and gout. J Hand Surg Br. 1999:24:363-365.
22. Kahn SJ, Sherry DD. Kienbock's disease--avascular necrosis of the carpal lunate bone--in a 7-year-old girl with dermatomyositis. Clin Pediatr (Phila). 1994,33:752-754,

23. Lichtman DM, Mack GR, MacDonald RI et al. Kienbock's disease: the role of silicone replacement arthroplasty. Bone Joint Surg Am. 1977;59:899-908.

24. Gelberman RH, Panagis JS, Taleisnik $J$ et al. The arteria anatomy of the human carpus. Part I: The extraosseous vascularity. J Hand Surg Am. 1983;8:367-375.

25. Lamas C, Carrera A, Proubasta I et al. The anatomy and vascularity of the lunate: considerations applied to Kienbock's disease. Chir Main. 2007;26:13-20.

26. Lee ML. The intraosseus arterial pattern of the carpal lunate bone and its relation to avascular necrosis. Acta Orthop Scand. 1963;33:43-55.

27. Panagis JS, Gelberman RH, Taleisnik J et al. The arteria anatomy of the human carpus. Part II: The intraosseous vascularity. J Hand Surg Am. 1983:8:375-382.

28. Gelberman RH, Salamon PB, Jurist JM et al Unar variance in Kienbock's disease J Bone Joint Surg Am. 1975:57:074676.

29. Chung KC, Spilson MS, Kim MH. Is negative ulnar variance a risk factor for Kienbock's disease? A meta-analysis. Ann Plast Surg. 2001:47:494-499.

30. D'Hoore K, De Smet L, Verellen $K$, et al. Negative Ulnar Variance is Not a Risk Factor for Kienbock's Disease. Hand Surg 1994;19A:229-231.

31. Ledoux $P$, Lamblin $D$, Wuilbaut $A$ et al. A finite-element analysis of Kienbock's disease. J Hand Surg Eur Vol. 2008;33:286-291

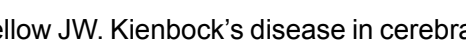
palsy. J Bone Joint Surg Br. 1977;59:363-365.

3. Joji S, Mizuseki T, Katayama Set al. Aetiology of Kienbock's disease based on a study of the condition among patients with cerebral palsy. J Hand Surg Br. 1993;18:294-298.

34. Findley TW, Halpern D, Easton JK. Wrist subluxation in juvenile rheumatoid arthritis: Pathophysiology an management. Arch Phys Med Rehabil 1983;64:69-74.

35. Evans DM, Ansell BM, Hall MA. The wrist in juvenile arthritis. J Hand Surg [Br]. 1991;16:293-304.
Nicholas M. Desy, M.D.C.M. is a third year resident in Orthopaedic Surgery at McGill University. He obtained a B.Sc. in Microbiology and Immunology from McGill University. He then completed his medical degree in 2008 from McGill University.

Mitchell Bernstein, M.D. is a fourth year resident in Orthopaedic Surgery at McGill University. He received a B.Sc. in Microbiology and Immunology from McGill University followed by an M.D. in Chicago.

Edward J. Harvey M.D., M.Sc. is an Associate Professor of Surgery in the department of Orthopaedic Surgery at McGill University. He is the Chief of Orthopaedic Trauma and Hand and Microvascular Surgery. He is also a co-director of the JTN Wong Labs for Bone Engineering where a large part of his research focuses on osteonecrosis and bone healing.

Elizabeth Hazel, M.D. is an Assistant Professor of Medicine in the division of Rheumatology at McGill University. She completed her Internal Medicine and Rheumatology training at McGill University. Her interests include patients with juvenile idiopathic arthritis. 